\title{
SOUTH CAROLINA HEALTH DISPARITIES - SOLUTIONS
}

For too many Americans, life expectancy is impacted by gender, income, ethnicity, education and location. AARP South Carolina is fighting to advocate for

programs that enable people to live and age with dignity and purpose.

\section{Greater public health efforts are needed in Black communities}

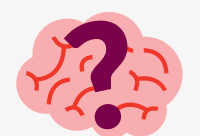

ALZHEIMER'S/DEMENTIA



HEART DISEASE

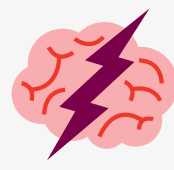

STROKE

Hypertension plays a large role in heart disease and stroke as well as Alzheimer's disease and related dementias. More effort is needed to reduce the high rates of hypertension among Black people.

There is a need to expand dental care to Black communities

Tooth decay and Tooth loss are risk factors for various chronic diseases such as heart disease as well as Alzheimer's disease and related dementias.

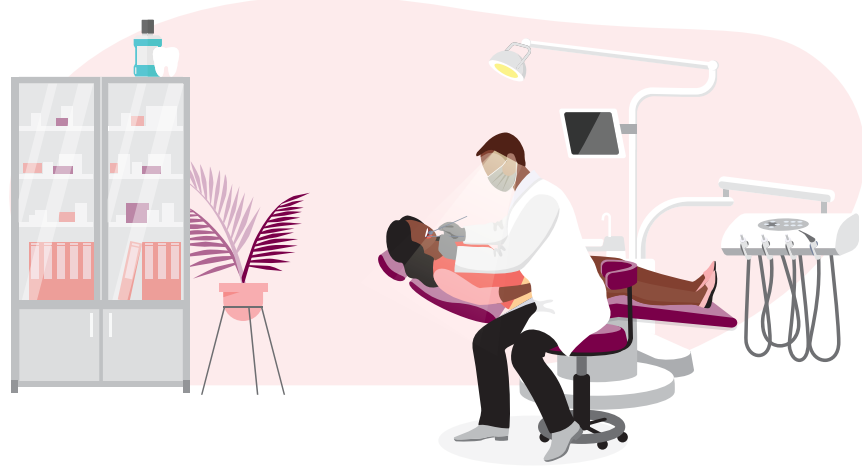

Targeted, coordinated and culturally appropriate healthcare and education should be prioritized in Black communities for:

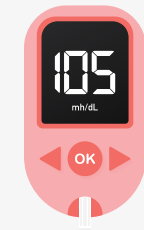

DIABETES

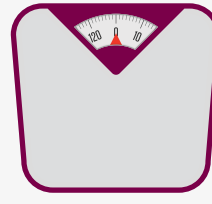

OBESITY

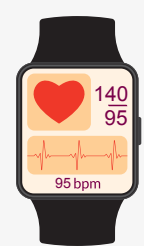

HYPERTENSION
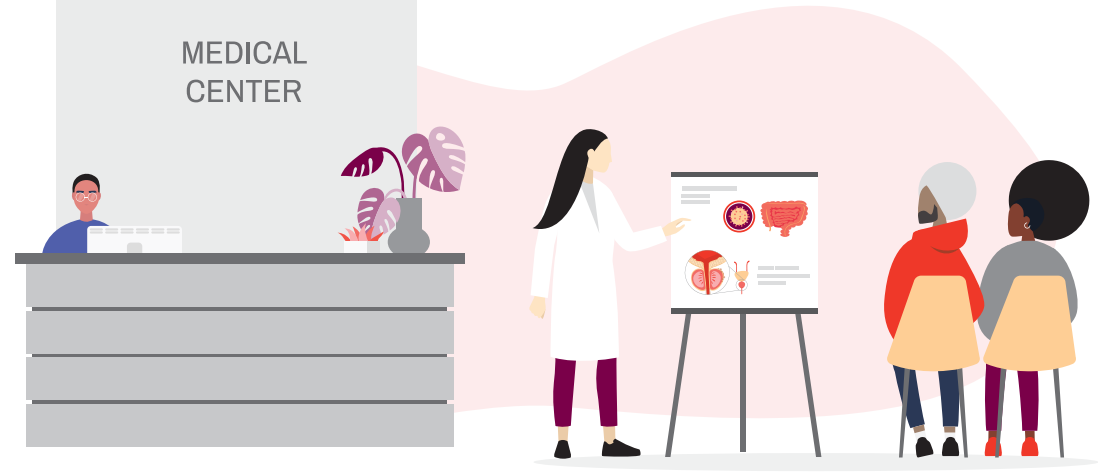

\section{Black communities need concentrated cancer outreach and education}

An increase in awareness and outreach would help provide access to screenings for colorectal cance and prostate specific antigen or PSAs.

\section{Creative coordinated solutions through multi-agency collaboration}

are needed to address social determinants of health that significantly contribute to health disparities in older Black people

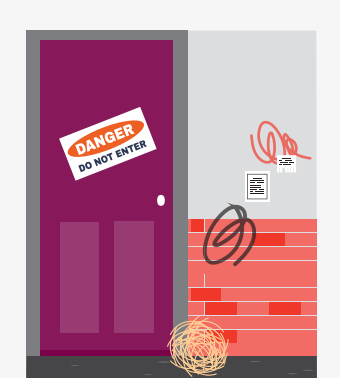

UNSAFE NEIGHBORHOODS

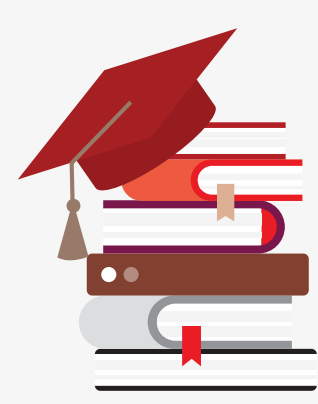

LACK OF HIGH SCHOOL EDUCATION

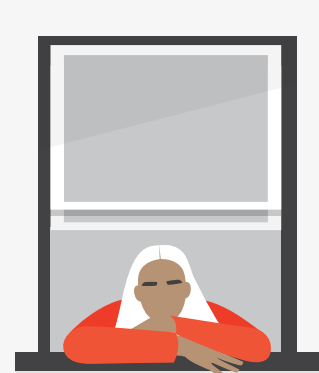

POOR HOUSING

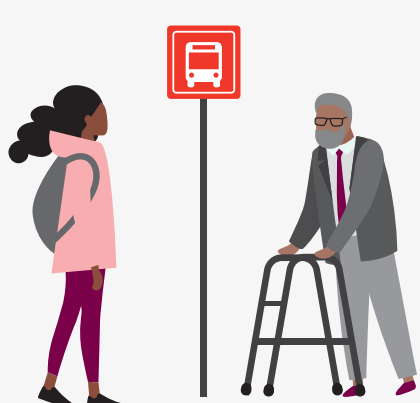

LACK OF TRANSPORTATION 